\title{
Mild Hypothermia after Severe Transient Hypoxia-Ischemia Ameliorates Delayed Cerebral Energy Failure in the Newborn Piglet
}

\author{
MARIANNE THORESEN, JULIET PENRICE, ANN LOREK, E. B. CADY, MARZENA \\ WYLEZINSKA, V. KIRKBRIDE, C. E. COOPER, G. C. BROWN, A. D. EDWARDS, J. S. WYATT, \\ AND E. O. R. REYNOLDS
}

\begin{abstract}
Departments of Paediatrics [J.P., A.L., V.K., C.E.C., J.S.W., E.O.R.R.] and Biochemistry [G.C.B.], University College London; Department of Medical Physics and Bioengineering, University College London Hospitals NHS Trust [E.B.C., M.W.]; Department of Paediatrics and Neonatal Medicine, Royal Postgraduate Medical School [A.D.E.], London, United Kingdom; and Departments of Paediatric and Surgical Research, Rikshospitalet, Oslo, Norway [M.T.]
\end{abstract}

thermic and normothermic groups. In the normothermic group, $[\mathrm{PCr}] /[\mathrm{Pi}]$ and $[\mathrm{NTP}] /[\mathrm{EPP}]$ recovered after the acute insult and then fell again. Minimum values for these variables observed between 24 and $48 \mathrm{~h}$ were significantly higher in the hypothermic group and not significantly different from the control values $(p<$ 0.05 , analysis of variance). A large reduction in secondary energy failure relative to the extent of the primary insult was shown and no further fall in either $[\mathrm{PCr}] /[\mathrm{Pi}]$ or $[\mathrm{NTP}] /[\mathrm{EPP}]$ took place up to $64 \mathrm{~h}$ in the hypothermic piglets. We conclude that mild hypothermia after a severe acute cerebral hypoxicischemic insult ameliorated delayed energy failure. (Pediatr Res 37: 667-670, 1995)

$\quad$ Abbreviations
EPP, exchangeable phosphate pool
MABP, mean arterial blood pressure
NTP, nucleotide triphosphate
31P MRS, phosphorus magnetic resonance spectroscopy
PCr, phosphocreatine
Pi, inorganic orthophosphate

Cerebral energy metabolism, assessed by ${ }^{31} \mathrm{P} \mathrm{MRS}$, in human infants who suffer severe birth asphyxia is usually normal on the first day of life (1). Later, impairment of cerebral metabolism develops, as shown by falling $[\mathrm{PCr}] /[\mathrm{Pi}]$ and sometimes falling [NTP] (which is composed largely of ATP). This impairment, which evolves in spite of normal cerebral intra-

Received for rapid publication November 29, 1994; accepted January 23, 1995

Correspondence: Dr. Juliet Penrice, Department of Paediatrics, University College London Medical School, Rayne Institute, University Street, London WC1E 6JJ,UK.

Supported by the Medical Research Council, UK, the Wellcome Trust, the Norwegian Research Council, the Laerdal Foundation for Acute Medicine, and the Norwegian SIDS Society. cellular $\mathrm{pH}$, arterial $\mathrm{Po}_{2}, \mathrm{MABP}$, and blood glucose concentration, was termed "delayed" or "secondary" energy failure, on the presumption that it was initiated by a preceding "primary" episode of energy impairment occurring before birth which had resolved with resuscitation. The severity of secondary energy failure is closely related to the chances of death or severe neurodevelopmental disability and microcephaly (1).

If the primary insult cannot be avoided by appropriate obstetric interventions, then it may be possible to interrupt the progression to secondary energy failure and its associated delayed neuronal death (2). One approach is to induce hypothermia. Deep hypothermia during hypoxia-ischemia is 
neuroprotective (3), but to be clinically useful in asphyxiated infants, hypothermia should preferably be mild and must be effective when started after the acute insult. Evidence for or against a potentially beneficial effect is very conflicting (4-7).

We have recently demonstrated that the progression from primary to secondary cerebral energy failure could be reproduced in the newborn piglet, and that the severity of the primary and secondary phases were directly related (8). The purpose of the present investigation was to test, in the same model, the hypothesis that mild hypothermia started immediately after a severe transient cerebral hypoxic-ischemic insult would reduce the severity of the subsequent secondary energy failure.

\section{METHODS}

These studies were carried out with Home Office approval and according to UK guidelines. Six healthy Large White piglets weighing $1.36-2.06 \mathrm{~kg}$ (median $1.61 \mathrm{~kg}$ ) aged $<24 \mathrm{~h}$ were studied. Full details of the methods used in the maintenance and monitoring of the piglets including observations of the brain by ${ }^{31} \mathrm{P}$ MRS, and of the procedures used to impose a severe transient hypoxic-ischemic cerebral insult have been given previously (8). Briefly, anesthesia was induced by inhalation of $5 \%$ isoflurane followed by tracheostomy and ventilation with nitrous oxide, oxygen and isoflurane $(<1.5 \%)$. Rectal and tympanic (pediatric tympanic thermistor probe 400 series, Portex, Hythe, UK) temperatures were kept normal for newborn piglets, $38.5-39.0^{\circ} \mathrm{C}$. While inside the bore of the magnet the piglet was placed on a temperature-regulated water-filled mattress. Monitoring of vital functions and full intensive care were continued throughout.

${ }^{31} \boldsymbol{P}$ MRS. Spectra were acquired continuously with a 7 tesla Bruker Biospec spectrometer (Karlsruhe, Germany). A 25-mm diameter surface coil was centered on the intact scalp over the parietal lobes, so as to obtain fully relaxed spectra from approximately $4 \mathrm{~mL}$ of brain tissue. The acquisition conditions and analysis were as previously described (8). For calculations involving NTP, the $\beta$-triplet was used, because it contained no contributions from other metabolites. [NTP] was expressed as a fraction of the exchangeable phosphate pool [EPP] defined as $[\mathrm{Pi}]+[\mathrm{PCr}]+[(\gamma+\alpha+\beta)-\mathrm{NTP}]$.

Acute cerebral hypoxia-ischemia. After stable baseline observations inside the magnet for at least $60 \mathrm{~min}$ the piglets underwent a cerebral hypoxic-ischemic insult brought about by occluding the common carotid arteries and reducing the inspired oxygen fraction to 0.12 . The aim was to produce severe acute cerebral energy depletion as shown by a fall in [PCr] close to zero, and a fall in [NTP]/[EPP] to below about $30 \%$ of baseline. The animals were then resuscitated by releasing the carotid occlusion and temporarily increasing the inspired oxygen fraction before appropriate reduction to normalize arterial $\mathrm{PO}_{2}$. The duration of carotid occlusion was 45-98 (median 70) $\min$.

Hypothermia. Coincident with resuscitation, cooling was initiated by fanning and reducing the temperature of the water mattress. The time taken to reach the target rectal temperature of $35^{\circ} \mathrm{C}$ was 35 (19) min [mean (SD)]. After $12 \mathrm{~h}$ with rectal and tympanic temperatures of $35^{\circ} \mathrm{C}$, rewarming was started at the rate of $1^{\circ} \mathrm{C} \cdot \mathrm{h}^{-1}$ until normothermia was resumed. Observations were then continued for at least a further $48 \mathrm{~h}$. Three piglets required infusions of dopamine $\left(5-10 \mu \mathrm{g} \cdot \mathrm{kg}^{-1} \cdot \mathrm{min}^{-1}\right)$ for between 2.5 and $11 \mathrm{~h}$ to keep MABP above $4.6 \mathrm{kPa}$.

Neuropathology. At the end of the study, animals were killed by anesthetic overdose. The brains were perfusion-fixed using $1 \%$ paraformaldehyde in PBS and examined after staining with hematoxylin and eosin by workers unaware of the experimental conditions. A quantitative assessment of damage in the cingulate sulcus (that was within the sensitive volume of the surface coil) was undertaken. In each animal about 5,000 cells were counted. Cells were classified as nonviable if they showed intense uniform nuclear basophilia, chromatin condensation, or fragmentation, or the presence of apoptotic bodies and also if cytoplasmic eosinophilia combined with nuclear lysis was observed.

Data analysis. Results from the six hypothermic piglets were compared with data previously obtained from 12 piglets similarly subjected to transient hypoxia-ischemia but maintained normothermic, and from six sham-operated controls (8). Data were examined for normality and equality of variances, and statistically significant differences between the three groups were determined by parametric (one-way analysis of variance and Student-Newman-Keuls multiple comparison test) or nonparametric (Kruskal-Wallis analysis of variance and Dunn's multiple comparison test) methods as appropriate.

\section{RESULTS}

Figure 1 shows rectal and tympanic temperatures from one of the piglets. For the group of six piglets, mean (SD) rectal and tympanic temperatures were: during hypoxia-ischemia $38.9(0.3)^{\circ} \mathrm{C}$ and $38.1(0.2)^{\circ} \mathrm{C}$; during hypothermia 35.1 $(0.3)^{\circ} \mathrm{C}$, and $35.3(0.5)^{\circ} \mathrm{C}$; and during postinsult normothermia $38.5(0.1)^{\circ} \mathrm{C}$ and $38.8(0.4)^{\circ} \mathrm{C}$.

Figure 2 shows changes in [NTP]/[EPP] together with our previously published data from sham operated control piglets and piglets subjected to a cerebral hypoxic-ischemic insult produced in exactly the same way as the present study, but which were subsequently maintained normothermic (8). Mean values for $[\mathrm{PCr}] /[\mathrm{Pi}]$ are given in Table 1 . No significant

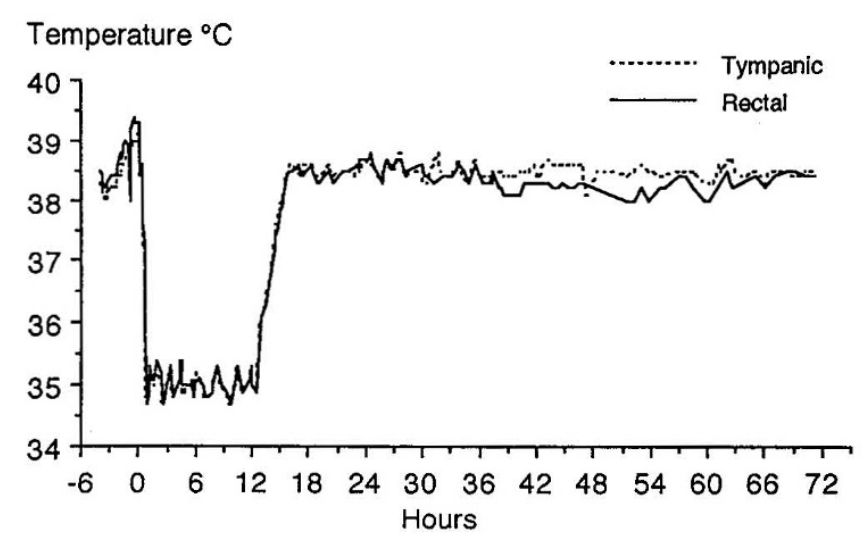

Figure 1. Rectal and tympanic temperature from a single piglet. Resuscitation commenced at $0 \mathrm{~h}$. 


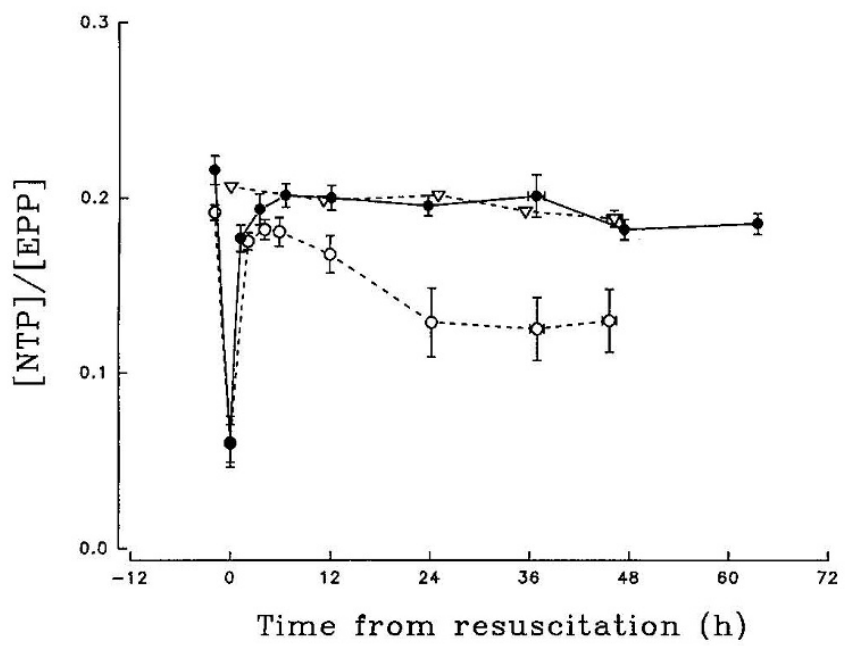

Figure 2. $[\mathrm{NTP}] /[\mathrm{EPP}]$ in the three groups of piglets. - hypothermia $(n=$ 6), $\mathrm{O}=$ normothermia $(n=12)$, and $\nabla=$ sham operated controls $(n=6)$. Values are means and SEM.

differences were detected between the three groups in baseline values of $[\mathrm{NTP}] /[\mathrm{EPP}]$ or $[\mathrm{PCr}] /[\mathrm{Pi}]$. When the minimum $[\mathrm{NTP}] /[\mathrm{EPP}]$ and minimum $[\mathrm{PCr}] /[\mathrm{Pi}]$ between 24 and $48 \mathrm{~h}$ were compared, the normothermic piglets had significantly lower values than the hypothermic and control piglets, whereas no differences were detected between hypothermic piglets and the control group ( $p<0.05$, analysis of variance).

To investigate whether the severity of the insult was comparable in the normothermic and hypothermic piglets, the time-integral of acute depletion of [NTP]/[EPP] from the onset of hypoxia-ischemia until $1 \mathrm{~h}$ after resuscitation was calculated. The mean values were similar, $0.12(0.06) \mathrm{h}$ in the hypothermic, and $0.11(0.05) \mathrm{h}$ in the normothermic piglets. The greater the time integral of depletion, the more severe the insult.

Figure 3 illustrates the relation between the severity of the primary insult (assessed by the time-integral of depletion of $[\mathrm{NTP}] /[\mathrm{EPP}])$ and the severity of secondary energy failure (assessed by the minimum $[\mathrm{PCr}] /[\mathrm{Pi}]$ value between 24 and $48 \mathrm{~h})$.

Physiologic variables remained stable and normal for piglets throughout the experiment. At $64 \mathrm{~h}$ after resuscitation mean (SD) arterial values were: $\mathrm{pH} 7.46(0.06) ; \mathrm{Po}_{2} 14.1(4.5) \mathrm{kPa}$; $\mathrm{PCO}_{2} 4.4(0.9) \mathrm{kPa}$; base excess $-0.8(3.2) \mathrm{mmol} \cdot \mathrm{L}^{-1}$; blood glucose $5.7(1.2) \mathrm{mmol} \cdot \mathrm{L}^{-1}$. Heart rate was $139(22) \mathrm{min}^{-1}$ and MABP was $7.5(0.9) \mathrm{kPa}$.

Neuropathology. The mean (SD) percentage of nonviable cells in the cingulate sulcus was $23(11) \%$ in normothermic piglets, $11(13) \%$ in animals treated with hypothermia and 5

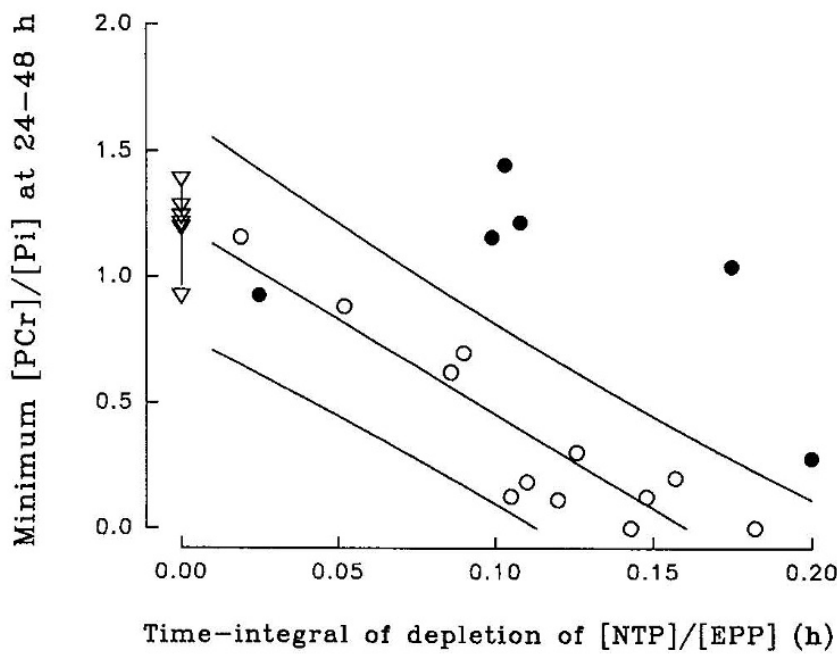

Figure 3. Relation between the severity of primary cerebral energy failure, indicated by the time integral of acute depletion of [NTP]/[EPP], and the severity of the subsequent secondary energy failure, indicated by the minimum $[\mathrm{PCr}] /[\mathrm{Pi}]$ value at $24-48 \mathrm{~h} . \bullet=$ hypothermia, $\mathrm{O}=$ normothermia, and $\nabla=$ sham operated controls. The regression line and $95 \%$ confidence limits for piglets maintained normothermic after hypoxia-ischemia are shown.

(4)\% in controls. The normothermic group was significantly different from both the hypothermic and the control group, and the hypothermic animals were not significantly different from controls ( $p<0.05$, analysis of variance). A full report of the histopathologic findings will be published separately.

\section{DISCUSSION}

Hypothermia has a long history in the treatment of birth asphyxia. Unresponsive infants were given cold baths in the last century. In the 1960s a number of centers claimed a reduction in brain damage (9) but the studies were not controlled. Subsequently, hypothermia went out of fashion, partly because Silverman et al. (10) had reported increased mortality and morbidity in premature infants who were hypothermic over a trial period of $5 \mathrm{~d}$.

Recently, studies of adult animals have suggested a worthwhile neuroprotective effect of mild $\left(34^{\circ} \mathrm{C}\right)$ or moderate $\left(30^{\circ} \mathrm{C}\right)$ postinsult hypothermia continued for $1-5$ h $(5,6,11,12)$. Overall, the sooner cooling was initiated, the shorter the duration required for effective treatment (5). Few studies of newborn animals have been done. Yager et al. (7) found no neuroprotective effect in 7-d-old rats subjected to unilateral ligation of the common carotid artery and $3 \mathrm{~h}$ of hypoxemia followed by cooling to either 34 or $31^{\circ} \mathrm{C}$ for $3 \mathrm{~h}$. In contrast, preliminary data from two other similar studies have demon-

Table 1. Cerebral [PCr]/[Pi] ratios in the hypothermic $(n=6)$ and normothermic $(n=12)$ hypoxic-ischemic groups

\begin{tabular}{lccccccc}
\hline & & \multicolumn{5}{c}{ Time (h) } \\
\cline { 3 - 7 } \multicolumn{1}{c}{ Group } & Baseline & 0 & 2 & 12 & 24 & 48 \\
\hline Hypothermic & $1.72(0.39)$ & $0.03(0.03)$ & $1.44(0.56)$ & $1.79(0.45)$ & $1.30(0.39)$ & $1.08(0.45)$ & $1.30(0.50)$ \\
Normothermic & $1.40(0.29)$ & $0.01(0.02)$ & $1.32(0.46)$ & $1.03(0.66)$ & $0.62(0.61)$ & $0.49(0.37)$ & $1.49(0.40)$ \\
Control & \multicolumn{2}{c}{$1.45(0.31)$} & $1.27(0.19)$ & $1.39(0.24)$ & $1.50(0.24)$ & \\
\hline
\end{tabular}

Times are from the start of resuscitation $(0 \mathrm{~h})$ in the normothermic and hypothermic groups, and from the start of observations in the controls. Values are mean (SD). At $48 \mathrm{~h}$ in the normothermic group $n=10$ because two animals had died with severe brain injury. 
strated cerebroprotection from postinsult hypothermia in seven- (13) and 21- (14) d-old rats.

The piglet was chosen for the present studies because it is large enough for observations to be made of a wide range of systemic, as well as cerebral variables, and its brain is comparable with that of the human infant. Reversible bilateral carotid occlusion, together with hypoxemia, was used to produce a severe transient cerebral hypoxic-ischemic insult. Cooling to $35^{\circ} \mathrm{C}$ was started simultaneously with the start of resuscitation and was continued for $12 \mathrm{~h}$. This experimental design was chosen on the premise that, if evidence of neuroprotection was found, the same approach might be clinically feasible in birthasphyxiated human infants. The hypothermic piglets were studied using the same methods as the previously reported piglets subjected to transient cerebral hypoxia-ischemia but kept normothermic and sham operated controls (8). Data from the hypothermic piglets could therefore be compared with previously established values from these two groups.

Figure 1 shows that hypothermia at the desired level was successfully achieved. The severity of the cerebral insult, judged by the depletion of [NTP]/[EPP], was similar in the hypothermic and normothermic groups. Evidence was then found that delayed energy failure was reduced in the hypothermic piglets as shown in Figures 2 and 3, and Table 1. [NTP]/ [EPP] remained at the levels obtained from sham operated controls, and the fall in [PCr]/[Pi] was less than in the normothermic piglets. The most likely explanation is that the hypothermia had prevented the evolution of energy impairment beyond the point where the creatine kinase reaction maintains [ATP] constant. No further deterioration in $[\mathrm{PCr}] /[\mathrm{Pi}]$ took place between 48 and $64 \mathrm{~h}$, showing that the hypothermia had not merely temporarily postponed energy failure.

As shown in Figure 3, a close correlation was found between the extent of acute energy depletion and the severity of secondary energy failure in normothermic piglets $(r=0.91)(8)$. Values above the $95 \%$ confidence limits for this relationship were found in five of the six hypothermic piglets and the value for the remaining animal which was within these limits, after a mild insult, fell at the lower limit of values observed in control piglets. In only one hypothermic piglet, which sustained the most severe primary insult, was the minimum $[\mathrm{PCr}] /[\mathrm{Pi}]$ below control values. These findings indicate a major reduction in the extent of secondary energy failure relative to the severity of the primary insult. The mechanisms involved in this protective effect are largely unknown. However, hypothermia is known to reduce the release of glutamate, modify regulatory enzymes, and protect protein synthesis.
Because secondary energy failure carries such a grave prognosis in human infants, the results of this study suggest that mild hypothermia might have a therapeutic role after birthasphyxia. Before considering studies of infants, it will be important for these results to be confirmed and the most effective protocol defined. Also, the potential value of hypothermia in ameliorating hypoxic-ischemic brain injury will have to be weighed against the possible disadvantages.

Acknowledgments. The authors thank R. F. Aldridge for technical assistance and Dr. Xu Yue for analysis of the neuropathology.

\section{REFERENCES}

1. Roth SC, Edwards AD, Cady EB, Delpy DT, Wyatt JS, Azzopardi D, Baudin J, Townsend J, Stewart AL, Reynolds EOR 1992 Relation between cerebral oxidative metabolism following birth asphyxia and neurodevelopmental outcome and brain growth at one year. Dev Med Child Neurol 34:285-295

2. Mehmet H, Yue X, Squier MV, Lorek A, Cady EB, Penrice J, Sarraf C, Wylezinska M, Kirkbride V, Cooper C, Brown GC, Wyatt JS, Reynolds EOR, Edwards AD 1994 Increased apoptosis in the cingulate sulcus of newborn piglets following transient hypoxia-ischemia is related to the degree of high energy phosphate depletion during the insult. Neurosci Lett 181:121-125

3. Ginsberg MD, Sternau LL, Globus MY-T, Dietrich WD, Busto R 1992 Therapeutic modulation of brain temperature: relevance to ischemic brain injury. Cerebrovasc Brain Metab Rev 4:189-225

4. Dietrich WD, Busto R, Alonso O, Globus MY-T, Ginsberg MD 1993 Intraischemic but not postischemic brain hypothermia protects chronically following global forebrain ischemia in rats. J Cereb Blood Flow Metab 13:541-549

5. Carroll M, Beek O 1992 Protection against hippocampal CA1 cell loss by postischemic hypothermia is dependent on delay of initiation and duration. Metab Brain Dis $7: 45-50$

6. Coimbra C, Wieloch $\mathrm{T} 1994$ Moderate hypothermia mitigates neuronal damage in the rat brain when initiated several hours following transient cerebral ischemia. Acta Neuropathol 87:325-331

7. Yager J, Towfighi J, Vannucci RC 1993 Influence of mild hypothermia on hypoxicischemic brain damage in the immature rat. Pediatr Res 34:525-529

8. Lorek A, Takei Y, Cady EB, Wyatt JS, Penrice J, Edwards AD, Peebles D, Wylezinska M, Owen-Reece H, Kirkbride V, Cooper CE, Aldridge RF, Roth S, Brown G, Delpy DT, Reynolds EOR 1994 Delayed ("secondary") cerebral energy failure after acute hypoxia-ischemia in the newborn piglet: continuous 48-hour studies by phosphorous magnetic resonance spectroscopy. Pediatr Res 36:699-706

9. Westin B, Nyberg R, Miller JA, Wedenberg E 1962 Hypothermia and transfusion with oxygenated blood in the treatment of asphyxia neonatorum. Acta Paediatr Scand(suppl 51):139:1-80

10. Silverman WA, Fertig JW, Berger AP 1958 The influence of the thermal environment upon the survival of newly born premature infants. Pediatrics 22:876-886

11. Zhang RL, Chopp M, Chen H, Garcia JH, Zhang ZG 1993 Postischemic (1 hour) hypothermia significantly reduces ischemic cell damage in rats subjected to 2 hours of middle cerebral artery occlusion. Stroke 24:1235-1240

12. Busto R, Dietrich WD, Globus MY-T, Ginsberg MD 1989 Postischemic moderate hypothermia inhibits CA1 hippocampal ischemic neuronal injury. Neurosci Lett 101:299-304

13. Bågenholm R, Løberg EM, Apricena F, Kjellmer I, Thoresen M 1994 Posthypoxic hypothermia provides cerebral protection against hypoxic-ischemic brain damage in the neonatal rat. Proceedings of the 14th European Congress of Perinatal Medicine, Helsinki, Finland: Kirjapaino Tapo Oy, 250

14. Blumberg RM, Sirimanne ES, Williams CE, Edwards AD, Gluckman PD 1994 Effect of delayed hypothermia on hypoxic-ischaemic cerebral injury in the developing rat. Proceedings of the 14th European Congress of Perinatal Medicine, Helsinki, Finland: Kirjapaino Tapo Oy, 249 